\title{
Patient satisfaction with intravenous PCA or epidural morphine
}

In many institutions postoperative patients may receive morphine for analgesia administered into the epidural space, epidural opioid analgesia (EOA), or through intravenous selfadministered patient-controlled analgesia pumps (PCA). Although a number of studies have compared the two approaches with regard to efficacy and side effects, there is less known with regard to patient satisfaction and its sources. In this study, 711 patients using PCA morphine and 205 patients receiving epidural morphine following a variety of gynaecological, urological, orthopaedic, and general surgical procedures rated their satisfaction with the method they used on a 0-10 verbal analogue satisfaction scale $(\theta=$ very dissatisfied; $10=$ very satisfied). A consecutive subset of 100 patients (50 from EOA group and 50 from the PCA group) underwent further evaluation to identify advantages and disadvantages of the technique used which contributed to their satisfaction and/or dissatisfaction. Overall satisfaction (mean $\pm S D$ ) in the two large groups was $8.6 \pm 1.8$ for $P C A$ and $9.0 \pm 1.5$ for EOA ( $P$ $<0.01)$. In the subset of 100 patients, there were differences between the EOA and PCA groups with regard to the advantages and disadvantages selected. Patients in the PCA group identified "personal control" and "method worked quickly" as advantages whereas patients receiving EOA selected "clear mind, "effective relief resting," and "effective relief while moving or coughing." The single disadvantage identified more frequently by PCA patients was "pain immediately after surgery before method became effective." Disadvantages identified more frequently by EOA patients were "side effects" and "poor pain relief." We conclude that overall patient satisfaction was high whether patients received PCA or EOA. The reasons for satisfaction or dissatisfaction differ depending on the method used.

\section{Key words}

ANALgeSIA: postoperative, PCA, epidural;

ANALGESICS: morphine;

PAIN: postoperative.

From the Department of Anesthesiology, University of

Washington, Seattle, WA 98195.

Address correspondence to: Dr. Kelly J. Egan, Department of Anesthesiology, RN-10, University of Washington School of Medicine, Seattle, WA 98195.

Accepted for publication 10th August, 1993.
Kelly J. Egan PhD, L. Brian Ready MD FRCPC

Dans de nombreuses institutions, les patients opérés reçoivent une analgésie à la morphine administrée soit dans l'espace épidural - analgésie épidurale par opiacés: (AEO) soit par une auto-administration intraveineuse - pompe d'analgésie contrôlée par le patient: (PCA). Bien que de nombreuses études aient comparé les deux approches et en ce qui concerne l'efficacité et les effets.secondaires, on en sait moins sur la satisfaction des patients et leurs raisons. Dans cette étude, 711 patients sous PCA à la morphine et 205 patients sous épidurale à la morphine évaluent leur satisfaction par une échelle analogue verbale entre 0 et $1010=$ très insatisfait, $10=$ très satisfait). Ils ont subi une variété d'interventions gynécologiques, urologiques, orthopédiques ou générales. Un sous-groupe ultérieur de 100 patients (50 du groupe AEO et 50 du groupe $P C A)$ est soumis à une évaluation secondaire pour identifier quels avantages et désavantages de la technique proposée contribuent ou non à leur satisfaction. La satisfaction globale (moyenne $\pm D S$ ) dans les deux groupes de départ est de 8,6 $\pm 1,8$ pour le PCA et 9,0 $\pm 1,5$ pour l'AEO $(P<0,01)$. Dans le sous groupe de 100 patients, il y a eu des différences entre les groupes $A E O$ et PCA en ce qui concerne les avantages et les désavantages proposés. Les patients dans le groupe PCA ont identifié comme avantage le "contrôle personnel " et la "rapidité de la méthode " tandis que les patients du groupe $A E O$ ont souligné la "clarté d'esprit ", le "soulagement de repos " et le "soulagement pendant la toux et le mouvement". Lunique désavantage identifié plus fréquemment par les patients PCA est la présence de "la douleur post-opératoire immédiate avant l'efficacité du PCA "; les désavantages identifiés plus fréquemment par les patients $A E O$ sont les "effets secondaires" et le "faible soulagement". Nous concluons que la satisfaction globale est élevée, que le patient soit sous PCA ou AEO. Les raisons de satisfaction ou non différent en fonction de la méthode utilisée.

Although patient satisfaction with pain relief provided postoperatively is an important criterion by which an analgesic technique should be judged, little has been published on this topic. 1,2 Pain relief, whether assessed by a simple visual analogue scale or by more elaborate selfreport measures, might logically be expected to contribute to satisfaction but may only be part of the equation. Some studies suggest that factors other than analgesia can play 
a role in patients' assessment of the success of postoperative pain management. ${ }^{3,4}$ If pain is relieved, but other aspects of the analgesic delivery system are aversive, the level of patient satisfaction may be low. Side effects created or exacerbated by analgesic therapy can be so distressing to patients that more pain with fewer side effects is preferred. ${ }^{5,6}$ Several studies have demonstrated that patients who control their own level of pain by selfmedication using patient-controlled analgesia (PCA) may choose to use less drug and accept higher pain levels rather than experience more side effects. ${ }^{1,7,8}$ In addition to analgesia and side effects, other aspects of pain therapy may contribute to patients' satisfaction following surgery. Some patients value maintaining control over analgesia whereas others prefer the physician and nurse to provide them with analgesics on a scheduled or "as needed" basis. ${ }^{8-10}$ Optimal pain management, including patient satisfaction, depends on addressing psychological as well as pharmacological needs.

Patient-controlled analgesia and epidural opioid analgesia are alternatives to traditional intramuscular opioid injections for postoperative pain, and have achieved rapid acceptance in major medical centres. ${ }^{11-13}$ When both epidural opioids and intravenous PCA are routinely available for postoperative pain relief, physicians frequently face a choice between these two popular alternatives. Although some types of surgical pain appear to be more effectively treated with epidural opioids, ${ }^{14-16}$ often the choice of analgesic therapy is based on other factors. The purpose of this study was to determine which aspects of these two methods of pain relief were seen as advantages or disadvantages by patients using them after surgery.

\section{Methods}

The anesthesiology-based Acute Pain Service (APS) at the University of Washington Medical Center was established to manage postoperative and other forms of acute pain. Postoperative analgesia for individual patients is planned by the operating room anesthetist during the preanaesthetic visit.

When epidural opioid analgesia (EOA) is recommended, an epidural catheter is inserted preoperatively and tested with a local anaesthetic to confirm correct placement. Injection or infusion of a local anaesthetic is used during surgery in combination with either sedation or general anaesthesia. The initial epidural opioid dose (frequently morphine) is given at least one hour before the completion of surgery. Under the direction of the APS, both the dose of morphine and time interval between injections may be varied to ensure optimal patient comfort. This represents a process of titration for each individual patient to define the minimum effective epi- dural morphine dose and longest interval between doses that maintains satisfactory analgesia. The optimal injection interval is usually found to be between 6 and 12 $\mathrm{hr}$. Supplemental epidural fentanyl (usually $50 \mu \mathrm{g} \mathrm{q} 3 \mathrm{hr}$ prn) is used during the first few hours of therapy while the effective morphine dose and injection interval are being defined. This fentanyl supplement is needed in about $30 \%$ of patients. Parenteral opioid supplements are not used. Treatment with epidural morphine is continued until a liquid diet is prescribed by the surgeon and pain is effectively controlled by an oral analgesic. Duration of epidural morphine therapy varies widely depending on pain severity and/or speed of return of bowel function. The most commonly used oral analgesics are preparations containing oxycodone or a combination of codeine and acetaminophen.

Intravenous PCA for postoperative analgesia is usually recommended for painful surgery following a general anaesthetic and is initiated in our institution when the patient is transferred to the surgical ward. Prior to surgery these patients are given a booklet explaining the optimal use of PCA. Immediately after surgery, patients in the recovery room receive intravenous opioid boluses titrated to provide satisfactory comfort. When they arrive on the surgical ward, they receive further instructions from their nurse regarding the use of PCA. The most commonly used opioid is morphine with the usual initial PCA variables as follows: incremental dose $-1 \mathrm{mg}$; lockout interval - eight minutes; four-hour limit - $30 \mathrm{mg}$. A basal infusion is not used initially. For inadequate analgesia, the incremental dose is increased and/or the lockout interval decreased as necessary. Treatment with PCA is continued until a liquid diet is prescribed by the surgeon and pain is effectively controlled by an oral analgesic. As in the case of patients receiving epidural morphine, the duration of PCA therapy varies widely depending on pain severity and/or speed of return of bowel function.

Patients receiving either form of care are seen by the APS a minimum of twice a day and as many additional times as necessary to provide optimal analgesia. On scheduled rounds, pain relief and side effects are evaluated and patient education is directed toward encouraging pain reporting and effective use of the available treatment. The average amount of time spent by the APS with patients receiving EOA or PCA is the same. A similar amount of time related to the provision of analgesia is also spent with both groups by ward nurses. ${ }^{17}$

As part of current practice of the APS, information collected on the day that care is terminated includes a 0 to 10 verbal analogue patient satisfaction score $0=$ "very dissatisfied with pain relief provided"; $10=$ "very satisfied with pain relief provided"). With the approval of the Human Subjects Review Committee, these obser- 
TABLE Reasons for patient satisfaction and dissatisfaction while receiving postoperative intravenous PCA morphine or epidural morphine

\begin{tabular}{|c|c|c|c|c|}
\hline Item & $\begin{array}{l}\text { Endorsements from } \\
\text { PCA morphine group } \\
(n=50)\end{array}$ & $\begin{array}{l}\text { Endorsements from } \\
\text { epidural morphine group } \\
(n=50)\end{array}$ & $\chi^{2}$ & $P$ \\
\hline \multicolumn{5}{|l|}{ Advantages } \\
\hline Worked quickly & 41 & 26 & 10.1 & $<0.01$ \\
\hline Provided personal control & 42 & 6 & 51.9 & $<0.0001$ \\
\hline Effective relief resting & 21 & 32 & 4.9 & $<0.05$ \\
\hline No painful injections & 23 & 30 & 2.0 & NS \\
\hline Clear mind & 9 & 21 & 6.9 & $<0.01$ \\
\hline No distressing side effects & 9 & 14 & 1.4 & NS \\
\hline Effective relief from moving/coughing & 1 & 11 & 9.5 & $<0.01$ \\
\hline Provides relaxation & 4 & 10 & 3.0 & NS \\
\hline \multicolumn{5}{|l|}{ Disadvantages } \\
\hline Causes side effects & 14 & 31 & 11.7 & $<0.001$ \\
\hline Pain after surgery before method became effective & 22 & 6 & 12.4 & $<0.001$ \\
\hline Insomnia & 17 & 17 & 0.05 & NS \\
\hline Sedation & 16 & 17 & 0.05 & NS \\
\hline Poor pain relief & 2 & 9 & 5.0 & $<0.05$ \\
\hline Dependence on others for care & 2 & 6 & 2.2 & NS \\
\hline Method worked slowly & 2 & 6 & 2.2 & NS \\
\hline Fear of addiction & 6 & 2 & 2.2 & NS \\
\hline Responsibility for own care & 3 & 0 & 3.1 & NS \\
\hline
\end{tabular}

vations are recorded on data collection sheets and entered in a computer database. For purposes of this study we reviewed, over a period of six months, a series of consecutive patients who received intravenous PCA morphine or epidural morphine all of whom provided a response to the satisfaction question. Patients receiving other opioids or drug mixtures by either route, and all patients converted from one form of therapy to the other for any reason were excluded. There were no other exclusion criteria.

A subset of 50 consecutive patients each from the EOA and PCA groups underwent further evaluation. This portion of the study was also approved by the institution's Human Subjects Review committee. On the postoperative day that they began using oral analgesics, they were approached by an independent data collector regarding their experience with their previous analgesic technique. Each was given a questionnaire that listed eight items which might be expected, from an earlier open-ended survey, to be associated with satisfaction with the provision of pain relief and nine items which might be expected to contribute to dissatisfaction (Appendix). Patients were asked to identify up to three items from each list that most applied to their experience. Thus each of the two groups of 50 patients could make a total of 150 selections of advantages and 150 selections of disadvantages of the method of analgesia they received.

Satisfaction scores from the larger sample were re- ported as means \pm standard deviation and were analysed with an unpaired $t$ test. A two-tailed critical significance level of 0.05 was employed. With the smaller sample of 100 respondents, $2 \times 2$ Chi square analysis, with a level for significance of 0.05 , was used to compare the analgesic methods (PCA or EOA) with regard to patients' perceptions of advantages and disadvantages.

\section{Results}

Satisfaction scores were obtained from a total of 711 patients receiving PCA intravenous morphine and 205 patients receiving epidural morphine following a wide variety of gynaecological, urological, orthopaedic, and general surgical procedures. Overall satisfaction (mean \pm $\mathrm{SD}$ ) in the two groups was $8.6 \pm 1.8$ for PCA and 9.0 \pm 1.5 for $\operatorname{EOA}(P<0.01)$.

In the 50-patient PCA group, the mean age was 46 yr; in the epidural group it was $55 \mathrm{yr}$. The male/female ratio in both groups was the same $(40 \% / 60 \%)$. The factors identified as advantages and disadvantages by each treatment group are shown in the Table and in Figures 1 and 2. Patients in the two groups selected different advantages and disadvantages depending on the postoperative analgesic technique they used. Patients who received PCA identified "personal control" and "method worked quickly" as advantages whereas patients receiving EOA selected "clear mind," "effective relief resting," and "effective relief moving and coughing." With regard to 


\section{Advantages of Method of Treatment}

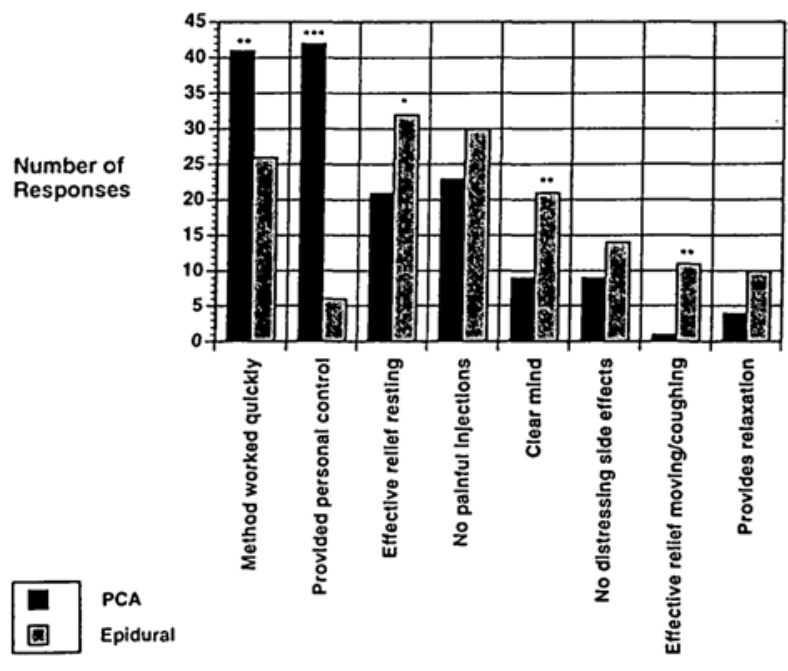

FIGURE 1 Number of responses from 50 patients receiving $\dot{N}$ PCA morphine and 50 patients receiving epidural morphine for each of eight possible reasons for satisfaction with pain relief provided. Each patient chose three responses. Significance of differences in the two treatment groups: ${ }^{*} P<0.05 ; * * P<0.01 ;{ }^{* * * P}<0.0001$.

disadvantages, PCA patients were concerned about "pain immediately after surgery" while EOA patients identified "side effects" and "poor pain relief." All patients in both groups chose three advantages they associated with their treatment. Some patients could not identify three disadvantages. Thirteen PCA patients $(26 \%)$ and 11 epidural patients $(22 \%)$ did not select any reasons for dissatisfaction; each of these stated they had no complaints about the technique they used.

\section{Discussion}

The use of both PCA and epidural morphine resulted in high overall satisfaction among the large group of postoperative patients who were surveyed. Although higher satisfaction was associated with epidural use, the magnitude of the difference ( 9.0 vs 8.6 ) is probably not clinically important. In the patient subgroups, however, it was found that satisfaction and dissatisfaction came from distinctly different sources.

The personal control aspect of PCA and the rapid onset of pain relief it provided were identified by patients using this method as the factors contributing most to their level of satisfaction. Although there was strong endorsement of some of the other factors, these were not different from those identified by patients using epidurals. A number of previous studies have also identified personal control associated with PCA to be related to a high level of patient satisfaction. ${ }^{1-4,8}$ In patients for whom

\section{Disadvantages of Method of Treatment}

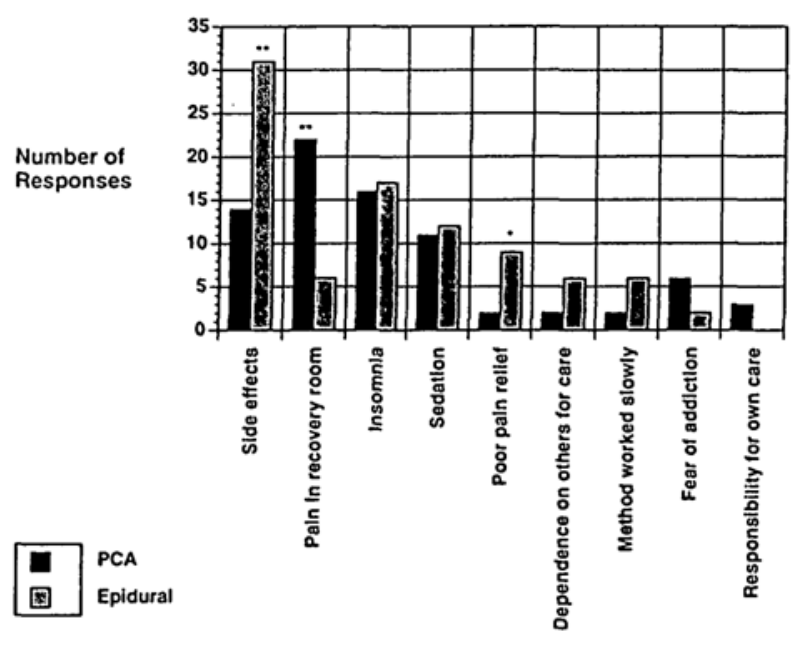

FIGURE 2 Number of responses from 50 patients receiving PCA morphine and 50 patients receiving epidural morphine for each of nine possible reasons for dissatisfaction with pain relief provided. Each patient chose up to three responses. Thirteen patients receiving i $v$ PCA and 11 patients receiving EOA stated that they could not identify any disadvantages associated with the method. Significance of differences in the two treatment groups: ${ }^{*} P<0.05 ; * * P<0.001$

control is important, PCA is likely to be a popular choice. Patients could conceivably be evaluated in this regard prior to surgery and their responses taken into consideration in choosing postoperative analgesic methods.

Patients with epidurals identified three advantages more often than patients using PCA: effective pain relief while resting, effective pain relief while coughing or moving, and having a clear mind. Compared with PCA, greater overall pain relief using epidural analgesia is consistent with a number of previous studies. ${ }^{14-16}$ This difference suggests the value of a recommendation for EOA in populations expected to have severe pain after surgery either at rest or during stimulation (e.g., coughing or ambulation). Although not different between groups, having no painful injections was important to over half of all patients.

Some of the differences observed in the two study groups may have been related to the older average age of the epidural patients. Having a "clear mind" was identified as an advantage by nearly half of the epidural patients compared with only $18 \%$ of the PCA patients. Older patients who are higher risk for sedation or confusion, might be more satisfied with an epidural technique since it requires less morphine administration than PCA. Older patients also might have preferred having their medications for pain administered by hospital staff, rather than by self-administration. 
Disadvantages were noted with both systems. The major disadvantage noted by 31 of 50 patients $(62 \%)$ using epidural morphine was unpleasant side effects. This was higher than the 14 of 50 patients (28\%) receiving PCA. One possible explanation is that PCA patients may have chosen to titrate morphine to a point where they experienced acceptable pain relief and at which few side effects occurred. In the epidural group, morphine was administered by medical personnel. Clearly, there is room for improvement in dealing with side effects, whether it be preventive (pre- or immediately postoperative medications) or more aggressive treatment of symptoms once they appear.

The PCA patients identified the problem of pain following surgery and before the method took effect. One solution might be to start PCA use in the recovery room, rather than waiting until patients are transferred to the surgical wards. Efforts to establish early analgesia with intravenous boluses of opioids in the recovery room were apparently not successful in some patients participating in this study. Approximately one third of patients in each group endorsed insomnia as a disadvantage while few individuals considered fear of addiction to be a problem. Twenty-six percent of PCA patients and 22\% of epidural patients were unable to identify any disadvantages with the system they used. This is consistent with the overall high level of satisfaction in both groups. While the majority (64\%) of the epidural group selected good pain relief as an advantage of the technique, poor pain relief was endorsed as a disadvantage by others.

The present study did not compare $i v$ PCA morphine with epidural morphine in terms of analgesic efficacy, but rather on the basis of satisfaction arising from advantages and disadvantages of the two methods of therapy. Such information should be considered when selecting a pain treatment method for patients in whom neither technique offers clear medical advantages. Better understanding of patient satisfaction and the factors which produce it may help to identify areas of postoperative analgesic therapy where improvements can be made.

Patient satisfaction with postoperative analgesic care is a complex issue. Although patients willingly offer ratings, it is by no means clear what such ratings represent. It is logical to assume, but certainly not known, that a number of factors might be involved. These could include analgesic efficacy, side effects, personal control over drug delivery, and recognition of the importance of pain and its effective treatment by physicians and nurses. In some cases the ratings may be applied to the therapists rather than to the therapy. If so, the amount of personal contact that occurs between pain therapists (both physicians and nurses) and patients might be an important determinant of satisfaction.
A promising new technique for pain relief is patientcontrolled epidural analgesia (PCEA), which combines some of the advantages of both of the methods compared in the present study. Patient satisfaction has been reported to be high among parturients using PCEA during labor. ${ }^{18}$ Options for postoperative analgesia have increased dramatically and will continue to increase. Further research is needed to understand better the complex entity of patient satisfaction.

\section{Appendix}

\section{Patient evaluation of postoperative pain control}

1 Advantages of method of pain control that you had:

(Circle the three most important advantages to you)

1 Method worked quickly (no waiting).

2 Good pain relief while resting.

3 Having personal control over pain relief.

4 Having a clear mind, no confusion.

5 Provided relaxation.

6 No painful injections.

7 No distressing side effects.

8 Good pain relief while moving or coughing.

2 Disadvantages of the method of pain control you had: (Circle the three most important disadvantages to you)

1 Side effects (nausea, itching, hard to urinate).

2 Pain after surgery and before method became effective.

3 Poor pain relief.

4 Method worked slowly.

5 Depending on others to provide pain relief.

6 Drowsiness.

7 Too much responsibility for own care.

8 Fear of drug addiction.

9 Unable to sleep at night.

\section{References}

1 Eisenach JC, Grice SC, Dewan DM. Patient-controlled analgesia following cesarean section: a comparison with epidural and intramuscular narcotics. Anesthesiology 1988; 68: 444-8.

2 Harrison DM, Sinatra $R$, Morgese L, Chung JH. Epidural narcotic and patient-controlled analgesia for postcesarean section pain relief. Anesthesiology 1988; 68: 454-7.

3 Kluger MT, Owen H. Patients' expectations of patientcontrolled analgesia. Anaesthesia 1990; 45: 1072-4.

4 Owen H, McMillan V, Rogowski D. Postoperative pain therapy: a survey of patients' expectations and their experiences. Pain 1990; 41: 303-7.

5 Inturrisi $C E$. Clinical pharmacology of opioid analgesics. In: Oden RV (Ed.). Anesthesiology Clinics of North America. Philadelphia: W.B. Saunders, 1989; 33-49. 
6 Benedetti C, Butler S. Systemic analgesics. In: Bonica J (Ed.). The Management of Pain. Philadelphia: Lea \& Febiger, 1990; 1640-75.

7 Vickers $M$. Clinical trials of analgesic drugs. In: Harmer M, Rosen M, Vickers M. (Eds.). Patient-Controlled Analgesia. London: Blackwell Scientific Publications, 1985; 42-50.

8 Egan KJ. Psychological issues in postoperative pain. In: Oden RV (Ed.). Anesthesiology Clinics of North America. Philadelphia: W.B. Saunders, 1989; 183-92.

9 Bowers KS. Pain, anxiety, and perceived control. J Consult Clin Psychol 1968; 32: 596-602.

10 Chapman $C R$. Psychological factors in postoperative pain and their treatment. In: Covina B, Smith G (Eds.). Acute Pain. Butterworth International Medical Reviews, 1985; 22-41.

11 Ready LB, Oden R, Chadwick HS, et al. Development of an anesthesiology-based postoperative pain management service. Anesthesiology 1988; 68: 100-6.

12 Ramsey $D H$. Perioperative pain: establishing an analgesia service. In: Brown DL (Ed.). Problems in Anesthesia Perioperative Analgesia. Philadelphia: Lippincott, 1988; 321-6.

13 Berde C, Sethna NF, Masek B, Fosburg M, Rocklin S. Pediatric pain clinics: recommendations for their development. Pediatrician 1989; 16: 94-102.

14 Loper $K A$, Ready $L B$. Epidural morphine after anterior cruciate ligament repair: a comparison with patientcontrolled intravenous morphine. Anesth Analg 1989; 68: 350-2.

15 Loper KA, Ready LB, Nessly M, Rapp SE. Epidural morphine provides greater pain relief than patient-controlled intravenous morphine following cholecystectomy. Anesth Analg 1989; 69: 826-8.

16 Rapp SE, Ready LB, Greer BE. Postoperative pain management in gynecology oncology patients utilizing epidural opiate analgesia and patient-controlled analgesia. Gynecol Oncol 1989; 35: 341-4.

17 Ready LB. The economics of patient-controlled analgesia. In: Ferrante F, Ostheimer G, Covino B (Eds.). PatientControlled Analgesia. Cambridge, MA: Blackwell Scientific Publications, 1990; 191-7.

18 Gambling DR, Huber CJ, Berkowitz J, et al. Patientcontrolled epidural analgesia in labour: varying bolus dose and lockout interval. Can J Anaesth 1993; 40: 211-7. 